\title{
Consumption of Commercial Dietary Products over Natural Diet - Impact in COVID Pandemic
}

\author{
Rojaramani K. ${ }^{1}$, Prakash G. ${ }^{2 *}$, Thulasiram K. ${ }^{3}$, Sai Mythri Dintyala V. ${ }^{4}$, Nannam R. ${ }^{5}$ \\ DOI: https://doi.org/10.17511/ijmrr.2021.i04.07
}

\footnotetext{
${ }^{1}$ K Rojaramani, Associate Professor, Department of General Surgery, S. V. Medical College, Tirupati, Andhra Pradesh, India.

2* G V Prakash, Professor and Head of Department, Department of General Surgery, S. V. Medical College, Tirupati, Andhra Pradesh, India.

${ }^{3}$ K Thulasiram, Associate Professor, Department of Medicine, S. V. Medical College, Tirupati, Andhra Pradesh, India.

4 Venkata Satya Sai Mythri Dintyala, Junior resident, Department of General Surgery, Sri Venkateswara Ramnarayan Ruia Government General Hospital, Tirupati, Andhra Pardesh, India.
}

5 Rishitha Nannam, Final Year Postgraduate, Department of General Surgery, S. V. Medical College, Tirupati, Andhra Pradesh, India.

\begin{abstract}
Background: An adequate intake of essential minerals like selenium, iron, and zinc and the vitamins $A, C, D, E, B 6$, and $B 12$ are crucial to maintaining a healthy immune function. Commercial dietary products containing a mixture of some of the above-mentioned; nutrients may suffice the specific requirements in definitive groups of populations. The comprehensive impact on the Indian population with consumption of commercial dietary products in addition to natural dietary products; during the Corona Virus Disease (COVID) pandemic was assessed in this study. Methods: A crosssectional \& observational study was conducted in a group of 3699 subjects, who attended the COVID OP Department at Sri Venkateswara RamaNarayana Ruia Government General Hospital, Tirupati from the period of August and September 2020. The subjects were randomly selected and a questionnaire was posed. The data collected were analyzed using Microsoft Excel and SPSS software. Results: The percentage of the population consuming commercial dietary products in addition to natural dietary products was $15.865 \%$. Commonly used natural dietary products by the population were egg\& milk products, vegetables followed by fruits. In our study, a significant association between gender and consumption of commercial dietary products was noted. Conclusions: The usage of commercial dietary products in addition to natural dietary products can be recommended in specified population groups. The consumption of commercial dietary products in addition to natural dietary products was significant concerning the female gender.
\end{abstract}

Keywords: Commercial dietary products, Natural diet, Immunity, Gene - diet interactions

\section{Corresponding Author}

G V Prakash, Professor and Head of Department, Department of General Surgery, S. V. Medical College, Tirupati, Andhra Pradesh, India. Email: gvprakash@rediffmail.com

\section{How to Cite this Article}

Rojaramani k, Prakash G V, Thulasiram K, Dintyala VSM, Nannam R. Consumption of Commercial Dietary Products over Natural Diet - Impact in COVID Pandemic. Int J Med Res Rev. 2021;9(4):249256.

\section{Available From}

https://ijmrr.medresearch.in/index.php/ijmrr/article/ view/1317
To Browse

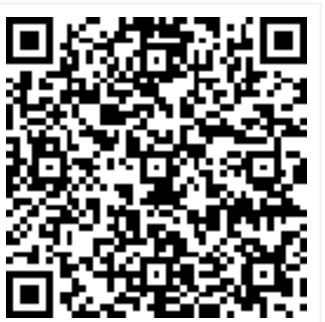

Manuscript Received 2021-07-28

Conflict of Interest No
Review Round 1 2021-08-08

Funding

$\mathrm{Nil}$

Review Round 2
2021-08-18
Ethical Approval
Yes

Yes
Review Round 3 2021-08-23

Plagiarism X-checker $5 \%$
Accepted 2021-08-28

Note

(c) 2021 by K Rojaramani, G V Prakash, K Thulasiram, Venkata Satya Sai Mythri Dintyala, Rishitha Nannam and Published by Siddharth Health Research and Social Welfare Society. This is an Open Access article licensed under a Creative Commons Attribution 4.0 International License https://creativecommons.org/licenses/by/4.0/ unported [CC BY 4.0] 


\section{Introduction}

Diet and immunity have an age-old link, as the deficiencies in the natural diet may impact the immune system to a greater extent. An adequate intake of essential minerals like selenium, iron, and zinc and the vitamins $A, C, D, E, B 6$, and $B 12$ are crucial to maintain a healthy immune function [1]. Commercial dietary products containing a mixture of some of the above-mentioned; nutrients may suffice the specific requirements in definitive groups of populations. In India, an inclination towards commercial dietary products was the recent trend. The comprehensive impact on the Indian population with consumption of commercial dietary products in addition to natural dietary products; during the COrona Virus Disease (COVID) pandemic was assessed. The presence of adulterants and contaminants of both biological and chemical nature in supplements was challenging and notable. [2]. Immunity was not a precise or reliable indicator of nutritional status yet functionally dependent. [3]. Immunity can be physiologically maintained with a natural diet rich in nutrients. [4]. During the COVID pandemic need for improvement in knowledge regarding diet plays a substantial role. The natural dietary patterns followed by the public and additional dietary products consumed may influence the scenario a lot. The need for commercial dietary products in specified groups of the population was predictable.

There were three main groups of constituents in foods viz., carbohydrates, proteins, fats, and their derivatives. Water along with varied organic \& inorganic substances like enzymes, minerals, antioxidants from other constituents. [5]. The basal metabolic rate describes the obligatory energy expenditure required to maintain metabolic functions in tissues and hence to sustain life. It is most closely predicted by lean body mass (i.e., total body mass - fat mass). [6]. The need for dietary nutrients to run the tissue metabolism smoothly for maintenance of immunological functions and the multitude of obesity affecting the immunological function was notable.

Vitamins were organic substances that were not synthesized in the body. They are broadly divided into fat-soluble $A, D, E, K$ vitamins and watersoluble vitamins lie B-complex and Vitamin C. [7]. Malnutrition is associated with defective immune function. Assessment of immunity is not a practical method in routine clinical practice. [8].
The immune system helps in discrimination of self from non-self. This discrimination is governed by natural or innate immunity and adaptive or acquired immunity. [9]. Dietary influence over the causation of chronic inflammatory disorders which disrupt innate immunity was familiar from age-old. Avoiding malnutrition is the basic goal in nutrition therapy as malnutrition increase morbidity and mortality of the disease process and delays recovery.

Immuno-modulators like Glutamine, Arginine, and Omega Fatty acids are also useful. [10]. The present study deciphers the outline view of nutritional ailments to be consumed during the COVID pandemic and their availability in natural dietary products. The role of dietary nutrients in the maintenance of immunity and in impeding the COVID pathogenesis was dealt with in detail. The nutritive patterns of the population regarding dietary products with gender were also studied. The current study aimed to make the public aware of the nutritional impact and benefits of a natural diet over commercial dietary products during the COVID pandemic.

This study listed the nutritional pattern of the population regarding commercial dietary products available in the market along with natural diet. Compared the nutritive values of commercial dietary products with natural dietary products. Also analyzed gender-specific consumption of Commercial Dietary Products in addition to natural dietary products. This study reviewed the current literature regarding diet that enhances immunity.

\section{Materials \& Methods}

A cross-sectional \& Observational study was conducted in a group of 3699 subjects, who attended the COVID OP Department at Sri Venkateswara RamNarayana Ruia Government General Hospital, a tertiary care centre located in Tirupati, during August and September 2020. The subjects were randomly selected and a questionnaire was posed to them after obtaining written informed consent. The data collected were analyzed using Microsoft Excel and SPSS software. A computerized search of the data related to specified commercial dietary products was performed and required data was obtained as per the manufacturer's disclosure. The nutritional data regarding natural dietary products were obtained from a computerized search of available literature and Indian Food Composition Tables published by the National Institute of Nutrition. 
Available literature was reviewed on nutritional elements to be consumed in view of COVID 19 infection, natural dietary products rich in those particular nutritional elements, the nutritive value of commercial dietary products, and their cost. The collected data were summarized as tables and graphs to study and to compare the nutritive value of natural dietary products with commercial dietary products.

Inclusion criteria: All the subjects in the age group between 10 to 80 years old, who were willing to participate were included in the study. Six commercial dietary products which were specified by subjects $\&$ available in the Indian market were studied. Their names were kept confidential and they have numbered accordingly from one to six. Six natural dietary products from different sections namely meat products, egg\&milk products, fruits, vegetables, leafy vegetables, and freshwater\&marine products available in the Indian market were selected randomly and studied.

Exclusion Criteria: All the subjects who were not willing to participate in the study were excluded.
Commercial dietary products and natural dietary products which were not available in the Indian market were excluded.

Statistical analysis: Data were entered into an excel sheet and analyzed by using software SPSS version 21.0. A Chi-square test was performed to find an association between gender and consumption of commercial dietary products in addition to a natural diet. Yates correction was applied wherever needed. P-value $<0.05$ was considered statistically significant.

This study was approved by the Institutional Ethics committee, S. V. Medical College, Tirupati. Informed written consent was obtained from all patients before their enrollment in this study.

\section{Results}

The present article covered the nutritive value of common natural dietary products in contrast with commercial dietary products. The details of the study were analyzed and shown in terms of statistical tables, percentages, and bar diagrams. Gender specificity to consumption of commercial dietary products was studied.

Table 1: Chart representing nutritive content of both commercial, natural dietary products.

\begin{tabular}{|c|c|c|c|c|c|c|c|}
\hline Name of the Product & Prot $(\mathrm{Gm})$ & Vit A (Mcg) & Vit D (Mcg) & Folic Acid (Mcg) & B $12(\mathrm{Mg})$ & $\mathrm{Cal}(\mathrm{Mg})$ & $\operatorname{Se}(M c g)$ \\
\hline CDP 1 & 18 & 318 & 3.75 & 75 & 0.76 & 800 & 15 \\
\hline CDP 2 & 14.1 & 458 & 4.7 & 100 & 1.5 & 386 & 18.5 \\
\hline CDP 3 & 20.1 & 364 & 4 & 127 & 1.48 & 258 & 16.4 \\
\hline CDP 4 & 15.2 & 556 & 6.17 & 380 & 2.96 & 617 & 42 \\
\hline CDP 5 & 20 & 866 & 3.3 & 240 & 1.6 & 1333 & 46.7 \\
\hline CDP 6 & 7 & 440 & 10 & 89 & 1.1 & 80 & 20 \\
\hline Chicken, Poultry, Liver & 21.57 & 3486 & 2.62 & 10.32 & 16.59 & 4.1 & 46.35 \\
\hline Country Hen, Leg, With Skin & 17.01 & 17.44 & 1.12 & 8.1 & 13.31 & 12.49 & 16.33 \\
\hline Goat, Liver & 20.32 & 15655 & 0.56 & 1.78 & 85.69 & 6.09 & 17.76 \\
\hline Sheep Leg & 21.42 & 9.93 & 2.14 & 1.81 & 2.7 & 5.92 & 43.3 \\
\hline Beef, Liver & 20.73 & 9119 & 0 & 1744 & 84 & 5.92 & 20.2 \\
\hline Pork, Liver & 19.89 & 8759 & 2.97 & ;954 & 18.67 & 5.52 & 33.49 \\
\hline Freshwater Rohu & 19.71 & 3.87 & 0.84 & 12.63 & 0.5 & 39.37 & 51.5 \\
\hline Salmon & 20.97 & 15.63 & 0.86 & 11.36 & 0.25 & 24.3 & 36.34 \\
\hline Marine Tiger Prawn & 14.85 & 6.55 & 1.02 & 15.37 & 0.55 & 37.81 & 46.95 \\
\hline Marine Crab & 10.23 & 5.02 & 0.63 & 23.04 & 9 & 128 & 34.8 \\
\hline Cat Fish & 22.18 & 14.08 & 1.42 & 11.36 & 1.5 & 5.54 & 42.33 \\
\hline Marine White Squid & 17.41 & 8.55 & 0.55 & 18.33 & 1.3 & 36.46 & 70.02 \\
\hline Oyster Mushroom & 19.04 & 109 & 0 & 10.4 & 0.09 & 23.61 & 0.058 \\
\hline Egg, Poultry, Yolk, Boiled & 16.13 & 456 & 3.04 & 110 & 2 & 120 & 38.57 \\
\hline Egg, Country Hen, Whole, Raw & 13.14 & 206 & 4.46 & 54.6 & 0.1 & 50.14 & 62.33 \\
\hline Khoa & 16.34 & 30.12 & 0.12 & 94.25 & 0 & 602 & 44.97 \\
\hline Paneer & 18.86 & 20.58 & 0.13 & 93.31 & 0.8 & 476 & 23.14 \\
\hline
\end{tabular}




\begin{tabular}{|l|l|l|l|l|l|l|l|}
\hline Milk, Cow & 3.26 & 58.25 & 0.12 & 7.03 & 0.14 & 118 & 1.5 \\
\hline
\end{tabular}

* Cal - calcium, CDP - Commercial Dietary Product, Gm - Gram, Mcg - Microgram, Mg - Milligram, Prot Proteins, Vit - Vitamin, Se - Selenium.

Table 1 depicts animal meat products as were the richest source of Vitamin A, Vitamin B12, and Folic
Acid. Folic acid is adequately available in eggs and milk products next to animal meat products. Egg and milk products were rich in calcium \& vitamin D while aquatic products were a good source of Vitamin E.

Table 2. chart representing nutritive content of natural dietary products

\begin{tabular}{|l|l|l|l|l|l|l|l|l|l|}
\hline Name of the Product & Prot (Gm) & Vit A (Mcg) & Vit D (Mcg) & Vit C (Mg) & Folic Acid $($ Mcg) & Iron (Mg) & Cal (Mg) & Zn (Mg) & Se (Mcg) \\
\hline Baby Corn & 2.69 & 0 & 31.2 & 8.59 & 45.53 & 1.45 & 76.51 & 1.13 & 0.22 \\
\hline Cluster Beans & 3.55 & 0 & 13.72 & 17.96 & 41.24 & 3.9 & 121 & 0.61 & 1.59 \\
\hline Plantain & 1.18 & 338 & 1.07 & 23.28 & 18.96 & 0.34 & 13.8 & 0.23 & 0.82 \\
\hline Onion Stalk & 2.07 & 0.6 & 6.81 & 27.23 & 57.61 & 3.09 & 31.12 & 0.99 & 5.22 \\
\hline Peas & 7.25 & 229.5 & 12.91 & 38.4 & 54.77 & 1.58 & 28.24 & 1.09 & 1.63 \\
\hline Drum Stick & 2.62 & 2.1 & 1.67 & 71.86 & 62.75 & 0.73 & 33.3 & 0.31 & 3.12 \\
\hline Ponnaganni Leaves & 5.29 & 160 & 0.65 & 103 & 11.18 & 3.88 & 388 & 0.99 & 17.19 \\
\hline Curry Leaves & 7.41 & 1050 & 11.7 & 6.04 & 1.77 & 8.67 & 659 & 1.18 & 17.25 \\
\hline Drumstick Leaves & 6.41 & 2269 & 14.3 & 108 & 2.26 & 4.56 & 314 & 0.72 & 5.95 \\
\hline Gogu Leaves Green & 1.86 & 1596 & 4.28 & 29.65 & 3.38 & 7.65 & 145 & 0.65 & 2.38 \\
\hline Agati & 8.01 & 450 & 4.02 & 121 & 7.75 & 4.36 & 901 & 0.53 & 30.7 \\
\hline Garden Cress & 5.6 & 95.8 & 0.55 & 42.75 & 12.01 & 6.19 & 217 & 1.52 & 8.08 \\
\hline
\end{tabular}

*Cal - calcium, Gm - Gram, Mcg - Microgram, Mg Milligram, Prot - Proteins, Se - Selenium, Vit Vitamin, Zn - Zinc.

Table 2 depicts leafy vegetables as were a rich source of Vit A, calcium, and selenium while
Specified vegetables are rich in folic acid. Leafy vegetables were also rich in Vitamin $\mathrm{K}$ \{ponnaganni $574 \mathrm{mcg}$, curry leaves $275 \mathrm{mcg}$, drumstick leaves $479 \mathrm{mcg}$, gogu leaves $433 \mathrm{mcg}$, agati 369mcg, garden cress $458 \mathrm{mcg}$ \}.

Table 3: chart representing the percentage of population consuming various dietary products.

\begin{tabular}{|l|l|l|l|l|l|}
\hline \multicolumn{1}{|c|}{ Name of the Product } & No. of Patients & Percentage & \multicolumn{1}{c|}{ Name of the Product } & No. of Patients & \multicolumn{1}{c|}{ Percentage } \\
\hline CDP 1 & 101 & $2.730 \%$ & EGG AND MILK PRODUCTS & 864 & $23.357 \%$ \\
\hline CDP 2 & 26 & $0.702 \%$ & FRUITS & 586 & $15.842 \%$ \\
\hline CDP 3 & 90 & $2.433 \%$ & MEAT & 583 & $15.761 \%$ \\
\hline CDP 4 & 50 & $1.351 \%$ & FRESH WATER \& MARINE PRODUCTS & 244 & 458 \\
\hline CDP 5 & 25 & $0.675 \%$ & LEAFY VEGETABLES & 700 & $6.596 \%$ \\
\hline CDP 5 & 97 & $2.622 \%$ & VEGETABLES & 264 & $12.381 \%$ \\
\hline others & 198 & $5.352 \%$ & others & 3699 & $7.137 \%$ \\
\hline Total & 587 & $15.865 \%$ & Total & & $100 \%$ \\
\hline
\end{tabular}

\section{* CDP - Commercial Dietary Products.}

In our study nutritive patterns of 3699 subjects were analyzed, which resulted in age, gender, and population-specific consumption of commonly available commercial dietary products while vegetables and egg, milk products were commonly consumed natural dietary products. During the COVID pandemic, the trend expected was a shift
From consumption of meat products to fruits and egg, milk products.

Table 4: chart representing the gender wise consumption of dietary products with in our population.

\begin{tabular}{|l|l|l|l|}
\hline \multicolumn{1}{|c|}{$\begin{array}{c}\text { Consumption of cdp's along with natural } \\
\text { dietary products }\end{array}$} & Females & Males & Tota \\
\hline Yes & 325 & 262 & 587 \\
\hline
\end{tabular}




\begin{tabular}{|l|l|l|l|}
\hline No & 1267 & 1895 & 3112 \\
\hline Total & 1592 & 2157 & 3699 \\
\hline
\end{tabular}

*Chi-Square value :47.4152; p- value <0.00001; significant at $p<0.05$

Chi-Square value with Yates correction: 46.7911; pvalue $<0.00001$; significant at $p<0.05$

Table 4 shows that there was a significant association between gender and consumption of commercial dietary products along with natural dietary products. This can be possibly explained by gender-specific needs like pregnancy, lactation, and postmenopausal state. The nutritive needs vary in these states while the impending risk of Coronary Artery Disease after menopause possibly might urge the consumption of commercial dietary products. $15.865 \%$ of the population were consuming commercial dietary products in addition to natural dietary products. The composition of proteins in the dietary product has to be considered along with the availability and composition of essential amino acids. Age and gender-appropriate proteins have to be consumed through a judicious mixture of varied natural dietary products.

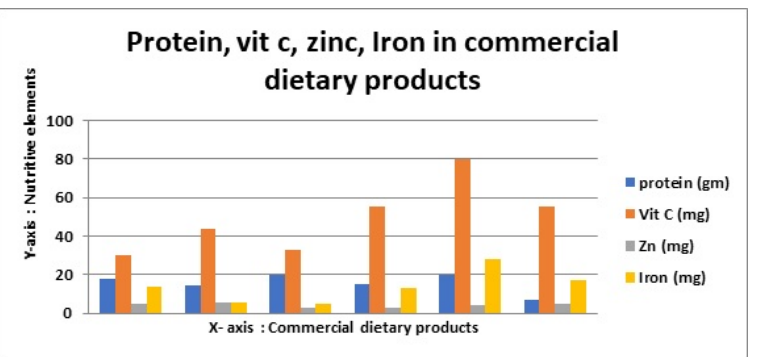

Figure 1: Bar chart representing protein and other nutritive elements available in Commercial Dietary Products from one to six.

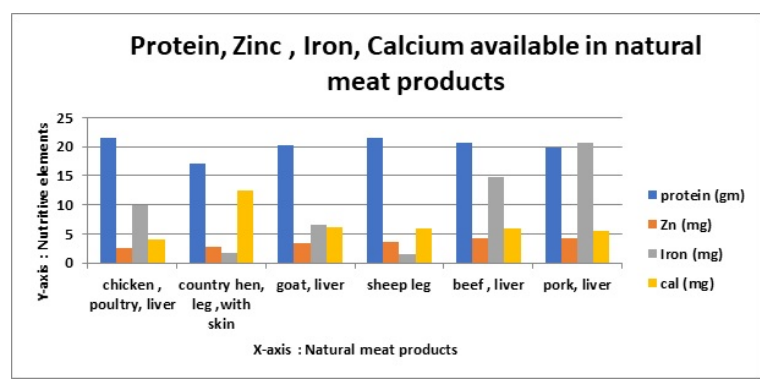

Figure 2: Bar chart representing protein and other nutritive elements available in natural meat products

Natural meat products serve the purpose of provision of nutrient-rich diet to be consumed during the COVID pandemic.
They were outstanding sources of Vitamin A, Folic acid, and rich sources of Selenium, vitamin B12. (Refer Fig. 1 and Fig. 2)

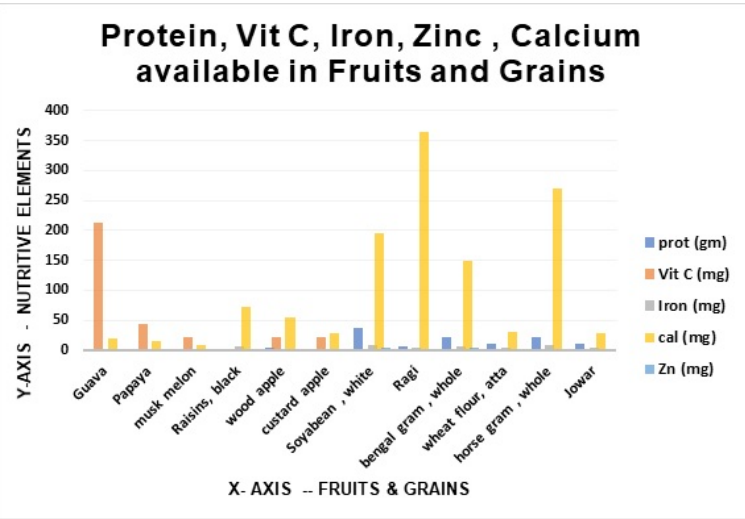

Figure 3: Bar chart representing protein and other nutritive elements available in Fruits \& Grains

Consumption of fruits mentioned in Fig. 3 has to be habituated to deliver the vitamins like Vitamin $A$, Vitamin D, Vitamin K, Folic acid, and micronutrients like selenium, magnesium. Papaya contains Vitamin D (11.4mcg), selenium $(12.78 \mathrm{mcg})$, vitamin A (447mcg) and Folic acid(60.9mcg). Muskmelon contains vitamin A (1014mcg) in notable amounts. In addition to the above-mentioned bar chart, Black Raisins are rich in Folic acid (3870 mcg) and magnesium (33.76mg). Wood apple is rich in Vitamin $\mathrm{D}(28 \mathrm{mcg})$ while custard apple is rich in Vitamin $\mathrm{k}$ (58mcg) along with magnesium (38mg). Grains are poor sources of vitamin B12, vitamin A, and vitamin $C$ while Bengal gram has vitamin $A$ (34.19) in it. (Refer Fig 3) White Soyabean and Ragi were rich in Vitamin $D\{(69.8 \mathrm{mcg})$ and $(41.46 \mathrm{mcg})$ respectively\}. Folic Acid is available at optimal amounts in soybean( $288 \mathrm{mcg})$, Bengal gram (233mcg), jowar(39.4), and ragi (34.6). Selenium is available in Bengal gram $(41.2 \mathrm{mcg})$, wheat flour atta(53.1mcg), Horse gram $(29.49 \mathrm{mcg})$, and Jowar (26.2mcg).

\section{Discussion}

From our study results obtained were $15.865 \%$ of the population were consuming commercial dietary products in addition to natural dietary products. Females were more in number to consume commercial dietary products in addition to natural dietary products. Animal meat products were outstanding sources of Vitamin A, Folic acid, and rich sources of proteins, Iron, Zinc, Selenium, vitamin B12. 
Fruits were rich in Vitamin C and Vitamin K. Egg and milk products were rich in calcium \& vitamin $D$ while aquatic products were a good source of Vitamin E. This suggests that balanced consumption of animal meat products, aquatic products, fruits in addition to egg\& milk products may cater to the need for maintenance of immune system healthier to fight the COVID pandemic in the economy. The other way of dietary nutritional enrichment was optimal consumption of specified fruits that were rich in Vitamins A, C, D, K, folic acid, magnesium in addition to grains that were good sources of selenium, proteins, calcium, vitamin D. Specified vegetables, leafy vegetables have to be consumed as a source of Iron and eggs for vitamin $E$.

Commercial dietary products may provide multiple micronutrients in varied quantities to cater to specified populations. For example, CDP 5 was rich in calcium, iron, and vitamin A while CDP 4 was rich in Folic acid and selenium. The vividity of available natural dietary products for consumption may cater to the need for personalized palatability of the person at a lower cost. The reasons for not opting for such a diet were lack of nutritional knowledge at the population level and influence of media through advertising commercial products.

An adequate intake of zinc, iron, and vitamins $A, B$ $12, B 6, C$, and $E$ is essential for the maintenance of immune function, as they impact the immune system through gene expression, cell activation, and signaling molecules modification. In addition, various dietary ingredients are determinants of gut microbial composition and subsequently shape the immune responses in the body. [11]. Both the immune impairments and the susceptibility to infection can be reversed by correcting the deficiency showing a causal relationship between the availability of specific nutrients and immune defenses.

This is recognized by the European Food Safety Authority which permits claims of 'maintenance of functions of the immune system' for vitamins A, B6, B12, C, D, and folate (vitamin B9) and for the trace elements zinc, iron, selenium, and copper. [12]. Zinc deficiency may affect both humoral and cellmediated immunity. Zinc deficiency may result in decreased Natural Killer cells activity, T Lymphocyte proliferation, InterLeukin 2 (IL2) production, which can be corrected with supplementation. [13]. Hence, daily intake of Zinc at low doses $<25 \mathrm{mg} /$ day on a long-term basis was recommended. [14].
Selenium works as an antioxidant through enzymes like Glutathione peroxidase, Thioredoxin reductase. Alexander et al, suggested that adequate preinfectious selenium status may protect against hyper inflammation during COVID infection. [14]. Studies have shown that Selenium deficiency may increase the virulence of certain viruses through mutations like poliovirus, murine influenza virus, and coxsackievirus. [13]. This aspect has yet to be studied in the case of COVID. Copper deficiency decreases the lymphocyte proliferation and IL2 production which can be reversed by supplementation. [13].

The precedence of natural diet over commercial products was notable regarding phytonutrients. The fruits, vegetables, and legumes rich in phytonutrients like flavonoids and polyphenol can exert anti-inflammatory effects. [15]. Jovic et al analyzed varied food samples and noted that spices, nuts like ground cloves, turmeric powder, ground ginger ground cinnamon, walnuts, ground mustard seeds were rich in antioxidants while meat and poultry products were poor sources of antioxidants. [15].

The production of InterLeukin - $1 \beta$ (IL-1 $\beta$ ) and InterLeukin-1 (IL-1) receptor antagonist by alveolar macrophages, in turn, neutrophilic infiltration was modulated by Retinoic acid which was implicated in the pathogenesis of Acute Respiratory Distress Syndrome (ARDS). [16]. The role of Vitamin C, to interfere with the COVID pathogenesis was the maintenance of alveolar barrier function through regulation of alveolar fluid clearance. Expression of protein channels like Aquaporin 5, Cystic Fibrosis Transmembrane Conductance Regulator, Epithelial Sodium Channel, etc over alveolar-capillary membrane was promoted by Vit C supplementation. [16]. Epidemiological studies suggested an inverse association between blood levels of $25(\mathrm{OH})-\mathrm{D} 3$ and inflammatory biomarkers like InterLeukin-6 (IL6) and C- Reactive Protein (CRP). [14]. Two Ecological studies concluded that the rate of COVID infection was high in countries at higher latitudes due to their lower Vitamin D status. [14].

Vitamin D promotes the differentiation of monocytes to macrophages and increases phagocytosis, superoxide production, and bacterial killing by innate immune cells. [13]. Vitamin D upregulates the expression of antioxidant genes, such as glutathione reductase thereby reducing free radicalinduced pulmonary damage and ARDS. [16]. 
Vitamin D Stimulates Thelper2 (Th2) cells and attenuates Th1 cells which evolve to reduce proinflammatory cytokines like Tumor Necrosis Factor a (TNFa) and Interferon $Y$ (IFNY) thereby decreasing the risk of ARDS. [12] With regards to COVID, vitamin D prevents a Tumor Growth Factor $\beta 1$ (TGF$\beta 1$ )-induced profibrotic phenotype of lung cells. [14]. Vitamin E supplementation reduces the production of superoxides thereby maintaining the balance between oxidants and antioxidants. Failure of biological membranes due to excessive lipid peroxidation may result in diffuse alveolar damage and ARDS. [16]. Vitamin $\mathrm{K}$ is an essential "switch" in balancing the coagulation and anti-coagulation process. The anticoagulant role of Vitamin $\mathrm{K}$ can be recognized through the activation of protein $C, S$ and $\mathrm{Z}$. Vitamin $\mathrm{K}$-dependent protein $\mathrm{C}$ activation can inhibit clotting factors $V$ and VIII which were responsible for clot generation. $\mathrm{K} 2$ acts as an immunosuppressive compound to modulate the expression of a multitude of pro-inflammatory cytokines such as TNF, InterLeukin-1a (IL-1a), IL-1 $\beta$ and suppresses IL- 6 release which was implicated in the pathogenesis of COVID.

Thus, vitamin $\mathrm{K}$ administration may reduce the risk for ARDS development in COVID-19 patients. [17]. As stated by Heiman and Greenway, "The more diverse the diet, the more diverse the microbiome and the more adaptable it will be to perturbations." This suggests the dietary intake of varieties of plant-based foods to modify the gut microflora, in turn, affects immunity.[15]. When fecal samples of COVID patients were collected and compared to that of healthy individuals, opportunistic pathogens and depleted commensals were observed in COVID patient samples while healthy subjects maintained a higher prevalence of Eubacterium, Roseburia, Lachnospiraceae Eubacterium, Faecalibacterium prausnitzii, Roseburia, and Lachnospiraceae. [18]. Indeed, the consumption of foods that are a source of fiber has been related to lower levels of inflammatory cytokines (CRP, TNF-a, and IL-6), as well as enhanced levels of short-chain fatty acids (SCFAs).SCFAs (acetate, propionate, and butyrate) exert their anti-inflammatory effect by inhibiting the release of pro-inflammatory molecules and by decreasing the expression of nuclear factor-kB (NFkB). [18].

Limitations: The complete composition of proteins present in commercial dietary products in comparison to natural dietary products was not studied in detail.
Only the essential ailments given COVID pandemic were studied and many other contents of natural dietary products were not included in the study. The study population might not represent that of the community

\section{Conclusions}

The consumption of commercial dietary products in addition to natural dietary products was significant concerning the female gender. Personalized natural dietary patterns are advised to the subjects instead of commercial dietary products which were manufactured in general to serve a group of population. Varied combinations of natural dietary products may serve the nutritional and in turn immunological need of the community during the COVID pandemic. Improvement in knowledge, attitude, and practices (KAP) regarding nutritional patterns of natural dietary products at the population level through the digital platform may be recommended during the COVID pandemic. Consumption of commercial dietary products in addition to natural dietary products was recommended whenever necessary such as in specified groups of the population.

\section{What does the study add to existing knowledge?}

Various combinations of natural food products may be used to meet the community's nutritional and, thus, immunological needs during the COVID pandemic. During the COVID pandemic, improving knowledge, attitudes, and practises (KAP) on nutritional patterns of natural dietary products at the population level through the digital platform may be encouraged.The female gender used a substantial amount of commercial dietary products in addition to natural dietary products. When necessary, such as among specified groups of the population, the use of commercial dietary products in addition to natural dietary products was encouraged.

\section{Author contributions}

Rojaramani K, Prakash GV collected the data, conducted this study, did data analysis. Sai Mythri Dintyala VS, Rishitha Nannam collected the data. Rojaramani K, Prakash GV, Thulasiram K, Sai Mythri Dintyala VS and Rishitha Nannam did manuscript drafting. All authors were involved in revising and approved the final version of the manuscript. 


\section{Reference}

01. Liebman BF. Dissenting Opinions in Nutrition Research. JAMA. 2020 Mar 10;323(10)1000. doi: 10.1001/jama.2020.0490 [Crossref][PubMed] [Google Scholar]

02. Dwyer JT, Coates PM, Smith MJ. Dietary Supplements- Regulatory Challenges and Research Resources. Nutrients. 2018 Jan 4;10(1)41. doi: 10.3390/nu10010041 [Crossref][PubMed][Google Scholar]

03. Norman Williams, P Ronan O'Connell, Andrew McCaskie, editors. Nutrition and fluid therapy, In Bailey and Love's Short practice of surgery. 27th ed, New York- CRC Press. 2018;279. [Crossref] [PubMed][Google Scholar]

04. Palmer, Nicholette D. "2 Genetic Determinants of Nutrient Processing". Nutrition and DiabetesPathophysiology and Management. (2019)27. [Crossref][PubMed][Google Scholar]

05. Potter, Norman N, Joseph H Hotchkiss. "Constituents of Foods: Properties and significance". Food Science, Springer, Boston, MA. 1995;24-45. [Crossref][PubMed][Google Scholar]

06. Nicholas A Boon, Micki R Colledg, Brian R walker. Environmental and nutritional factors in disease, In- Davidson's principles and practice of medicine. 20th ed, New York- Churchill Livingstone/Elsevier. 2006;108. [Crossref][PubMed] [Google Scholar]

07. Nicholas A Boon, Micki R Colledg, Brian R walker. Environmental and nutritional pathology, InDavidson's principles and practice of medicine. 20th ed, New York- Churchill Livingstone/Elsevier. 2006;121. [Crossref][PubMed][Google Scholar]

08. Norman Williams (Editor), P Ronan O'Connell (Editor), Andrew McCaskie (Editor). Nutrition and fluid therapy- ch 19; 27th edition. London, Newyork; CRC Press. Jan 2018;279; volume 1. [Crossref][PubMed][Google Scholar]

09. Seed Prem Nyati. Immunomodulators, InClinical pharmacology. 1st ed, India- Globalmedik. 2007;393. [Crossref][PubMed][Google Scholar]

10. Sriram Bhat M, Chapter F. In- SRB'S Manual of Surgery. 4th ed, New Delhi- Jaypee Brothers Medical Publishers. 2013;101. [Crossref][PubMed] [Google Scholar]
11. Aman, Faseeha, Sadia Masood. "How Nutrition can help to fight against COVID-19 Pandemic". Pakistan Journal of Medical Sciences. 36;COVID19S4(2020)S121. [Crossref][PubMed][Google Scholar]

12. Calder PC. Nutrition, immunity and COVID-19. BMJ Nutr Prev Health. 2020 May 20;3(1)74-92. Doi: 10.1136/bmjnph-2020-000085 [Crossref][PubMed] [Google Scholar]

13. Calder PC. Feeding the immune system. Proc Nutr Soc. 2013 Aug;72(3)299-309. Doi: $10.1017 /$ S0029665113001286 [Crossref][PubMed] [Google Scholar]

14. Alexander J, Tinkov A, Strand TA, Alehagen $U$, Skalny A, Aaseth J. Early Nutritional Interventions with Zinc, Selenium and Vitamin D for Raising AntiViral Resistance Against Progressive COVID-19. Nutrients. 2020 Aug 7;12(8)2358. doi: 10.3390/nu12082358 [Crossref][PubMed][Google Scholar]

15. Evans JM, Luby $R$, Lukaczer $D$, Rountree $R$, Stone PM, Guilliams TG, et al. The Functional Medicine Approach to COVID-19- Virus-Specific Nutraceutical and Botanical Agents. Integr Med (Encinitas). 2020 May 9;19(Suppl 1)34-42. [Crossref][PubMed][Google Scholar]

16. Jovic TH, Ali SR, Ibrahim N, Jessop ZM, Tarassoli SP, Dobbs TD, et al. Could Vitamins Help in the Fight Against COVID-19?. Nutrients. 2020 Aug 23;12(9)2550. doi: 10.3390/nu12092550 [Crossref] [PubMed][Google Scholar]

17. Janssen R, Visser MPJ, Dofferhoff ASM, Vermeer C, Janssens $\mathrm{W}$, Walk J. Vitamin $\mathrm{K}$ metabolism as the potential missing link between lung damage and thromboembolism in Coronavirus disease 2019. $\mathrm{Br}$ J Nutr. 2021 Jul 28;126(2)191-198. doi: $10.1017 / S 0007114520003979$ [Crossref][PubMed] [Google Scholar]

18. Fernández-Quintela $\mathrm{A}$, Milton-Laskibar $\mathrm{I}$, Trepiana J, Gómez-Zorita S, Kajarabille N, Léniz A, et al. Key Aspects in Nutritional Management of COVID-19 Patients. J Clin Med. 2020 Aug 10;9(8)2589. doi: 10.3390/jcm9082589 [Crossref] [PubMed][Google Scholar] 